\title{
Dynamical Effects of the Variable Tropopause
}

\author{
By Takashi Nitta* \\ Electronic Computation Center, Japan Meteorological Agency, Tokyo \\ (Manuscript received 22 December 1964, in revised form 4 March 1965)
}

\begin{abstract}
A computational model for large scale motions which extends to the stratosphere is designed. The model has the tropopause and ground surface, and is favorable in treating the interaction between the tropospheric and stratospheric motions. A special $\sigma$-coordinate in the vertical is used, and the tropopause is assumed to be a material surface at which $d \sigma / d t$ vanishes.

Fundamental equations of the model are illustrated, and energetical considerations are given. Particular interest is put in the interaction of kinetic energy between the troposphere and the stratosphere in the short term evolution of the atmospheric motion. Calculation based on the actual data is made for the vertical transfer of kinetic energy through the tropopause.

Analytical solutions of perturbations superimposed on the basic zonal current are obtained for barotropic and baroclinic models and compared with those of $p$-coordinate system. The kinetic energy transport in vertical as well as control of the false westward retrogression of the ultra-long wave, due to the non-vanishing vertical mean divergence in the troposphere, are shown. Modification of the criterion of baroclinic instability due to the existence of the stratosphere is discussed.
\end{abstract}

\section{Introduction}

Recently the atmospheric model of numerical weather prediction has been refined by introduction of more detailed physical processes in lower troposphere, such as the nonadiabatic heating and cooling, and the effect of orography.

It seems, however, that there remain several important problems unsolved. One of them is the extention of model toward the stratosphere, which will enable us to treat the ultralong waves more accurately. Gates (1957), Eliassen (1960) and Murakami (1964) have proposed atmospheric models for this purpose. Gates' model consists of two baroclinic layers (corresponding to the troposphere and the stratosphere) separated by a tropopause which is considered as a material surface. Eliassen has presented a quasi-Lagrangian model where the atmosphere is bounded by material surfaces, and the tropopause is chosen as one of

* Present address : National Meteorological Center, U.S. Weather, Bureau, Suitland, Md., U.S.A. coordinate planes. To include the stratosphere in the model atmosphere, Murakami has recommended a vertical $\sigma$-coordinate as $\sigma=p / p_{T}$ for the stratosphere, and $\sigma=\left(p-p_{T}\right) /\left(p_{S}-p_{T}\right)$ for the troposphere, where $p_{T}$ and $p_{S}$ stand for pressures at the tropopause and the ground surface respectively.

The purposes of the present paper are to see the features of the kinetic energy transfer through the tropopause and to examine the behaviors of the tropospheric disturbance under the variable tropopause, with special interest on very long wave, with respect to an atmospheric model extending to the stratosphere. In the following, we will use the $x$, $y, \sigma$-coordinate system as the same as that of Murakami, and will also use the assumption that the tropopause is a material surface.

At first we derive the fundamental equations and the energetical relations on the $\sigma$-coordinate. Secondly, the interaction between the troposphere and the stratosphere are considered, and calculations are made to see the short term vertical propagation of kinetic energy through the tropopause. Finally, we obtain 
wave solutions from the linearized equations, and discuss on their properties of the ultralong waves and the effect of the variable tropopause on the tropospheric motion. Comparisons are made between the forecast results by this model and by the conventional model of $p$-system.

\section{Coordinate and modelling assumption}

Nothing can be said about the maintenance of the tropopause without taking into account the radiational effect in the atmosphere. In the case of short range forecasting, however, incorporation of the influence of the stratosphere through the tropopause in an atmospheric model could be accomplished by assuming the existence of the stratosphere at initial time and keeping physical properties of the stratosphere from distortion, by some means, in the process of numerical calculation.

In the following discussion, we use the $\sigma-$ coordinate similar to that of Murakami, i.e.,
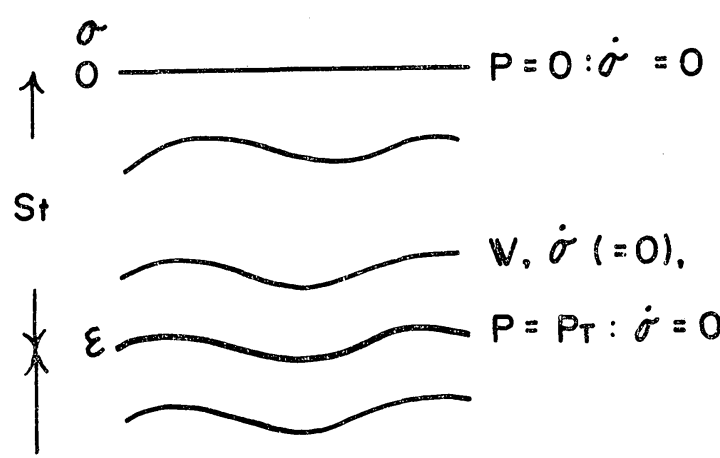

$\operatorname{Tr}$

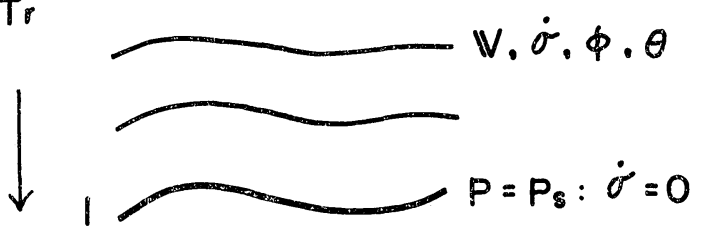

Fig. 1. Vertical resolution in $\sigma$-coordinate.

$$
\sigma=\varepsilon \frac{p}{p_{T}},\left(0 \leq p \leq p_{T}\right):
$$

in the stratosphere

and

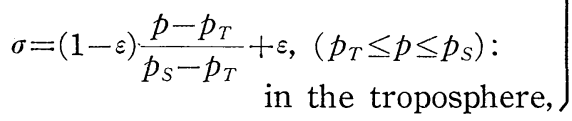

where $0<\varepsilon<1$, and $p_{T}$ denotes the pressure at the tropopause and $p_{S}$ that at the ground. The value of $\varepsilon$ is to be determined according to the degree of vertical resolution desired: for instance, $\varepsilon=1 / 2$ is suitable for representing the 2-layer model (the troposphere and the stratosphere), and $\varepsilon=1 / 3$ for 3-layer model (two layers in the troposphere and one in the stratosphere). Although there would be many versions of $\sigma$-coordinate other than mentioned above, we particularly choose (2.1) simply because $\sigma$ is linear with $p$ and then the difference of $\sigma$ corresponds to the mass between the two levels. This fact enables us to solve the problem easily. But on the other hand it requires an additional boundary condition on $\dot{\sigma}=d \sigma / d t$ at the internal surface, i.e., at the tropopause.

Concerning this point, we assume that the tropopause is a material surface; $\dot{\sigma}$ is zero at the level $\sigma=\varepsilon$. Moreover, it is also assumed that the atmosphere is isentropic in the stratosphere and accordingly $\dot{\sigma}$ vanishes on every coordinate plane.

\section{Fundamental equations and energy equa- tions}

Using the definition of $\sigma$, we can derive fundamental equations of motion and the thermal equations on $\sigma$-coordinate for the stratosphere $(S t)$ and the troposphere $(T r)$ as follows.

(1) Equation of motion

$S t: \frac{d \boldsymbol{V}}{d t}+f \boldsymbol{k} \times \boldsymbol{V}+\nabla \phi-\frac{\sigma}{p_{T}}\left(\frac{\partial \phi}{\partial \boldsymbol{\sigma}}\right) \nabla p_{T}=\boldsymbol{F}$,

$$
\begin{gathered}
T r: \frac{d \boldsymbol{V}}{d t}+f \boldsymbol{k} \times \boldsymbol{V}+\nabla \phi-\frac{1}{\pi}\left(\frac{\partial \phi}{\partial \sigma}\right) \\
\times \nabla\left(\sigma \pi+p_{T}-\varepsilon p_{S}\right)=\boldsymbol{F},
\end{gathered}
$$

where $\pi=p_{S}-p_{T}, \frac{d}{d t} \equiv \frac{\partial}{\partial t}+\boldsymbol{V} \cdot \nabla+\dot{\sigma} \frac{\partial}{\partial \sigma} \equiv \frac{d_{H}}{d t}$ $+\dot{\sigma} \frac{\partial}{\partial \sigma}, F$ shows a dissipation and other notations are as usual. $\dot{\sigma}$ relates to $\omega \equiv d p / d t$ as

$$
\begin{aligned}
& \text { St: } \quad \omega=\frac{1}{\varepsilon}\left(\sigma \frac{d_{H} p_{T}}{d t}+p_{T} \dot{\sigma}\right), \\
& \text { Tr: } \omega=\frac{1}{1-\varepsilon} \frac{d_{H}}{d t}\left(\sigma \pi+p_{T}-\varepsilon p_{S}\right)+\frac{\pi}{1-\varepsilon} \dot{\sigma} .
\end{aligned}
$$

(2) Continuity equation 


$$
\begin{aligned}
& \text { St: } \quad \frac{\partial}{\partial t} p_{T}+\nabla \cdot\left(p_{T} \boldsymbol{V}\right)+\frac{\partial}{\partial \sigma}\left(p_{T} \dot{\sigma}\right)=0, \\
& T r: \quad \frac{\partial}{\partial t} \pi+\nabla \cdot(\pi \boldsymbol{V})+\frac{\partial}{\partial \sigma}(\pi \dot{\sigma})=0 .
\end{aligned}
$$

Integration of (3.3) with $\sigma$ give the following formulae to determine $\dot{\sigma}, \partial p_{T} / \partial t$ and $\partial \pi / \partial t$.

$$
\begin{aligned}
S t: \quad p_{T} \dot{\sigma} & =-\int_{0}^{\sigma} \nabla \cdot\left(p_{T} \boldsymbol{V}\right) d \sigma-\sigma \frac{\partial p_{T}}{\partial t}, \\
\frac{\partial p_{T}}{\partial t} & =-\frac{1}{\varepsilon}\left\{\int_{0}^{\varepsilon} \nabla \cdot\left(p_{T} \boldsymbol{V}\right) d \sigma+p_{T} \dot{\boldsymbol{\sigma}}_{T}\right\},
\end{aligned}
$$

where $\dot{\sigma}_{T}=\left(\varepsilon / p_{T}\right)\left(\omega_{T}-d_{H} p_{T} / d t\right)$.

$$
\begin{gathered}
\text { Tr: } \pi \dot{\sigma}=\pi \dot{\sigma}_{T}-\int_{\varepsilon}^{\sigma} \nabla \cdot(\pi \boldsymbol{V}) d \sigma-(\sigma-\varepsilon) \frac{\partial \pi}{\partial t}, \\
\frac{\partial \pi}{\partial t}=\frac{1}{1-\varepsilon}\left\{\pi \dot{\sigma}_{T}-\int_{\varepsilon}^{1} \nabla \cdot(\pi \boldsymbol{V}) d \sigma\right\},
\end{gathered}
$$

where $\dot{\sigma}_{T}=((1-\varepsilon) / \pi)\left(\omega_{T}-d_{H} p_{T} / d t\right)$.

The relation that $\dot{\sigma}=0$ at $\sigma=0, \sigma=\varepsilon$ and $\sigma=1$ should be used if necessary.

(3) Thermal equation

St and $\operatorname{Tr}: \frac{d \theta}{d t}=\frac{1}{c_{p}}\left(\frac{p_{10}}{p}\right)^{\kappa} \frac{d Q}{d t}$,

where $\kappa=R / c_{p}$, and $d Q / d t$ shows non-adiabatic heating.

(4) Hydrostatic relation

St : $\frac{\partial \dot{\phi}}{\partial \sigma}=-\frac{R T}{\sigma}=-\frac{R}{\sigma}\left(\frac{\sigma p_{T}}{\varepsilon p_{10}}\right)^{\kappa} \theta$,

$\operatorname{Tr}: \frac{\partial \phi}{\partial \sigma}=-\frac{\pi R T}{\sigma \pi+p_{T}-\varepsilon p_{S}}$

$$
=-\frac{\pi R}{\sigma \pi+p_{T}-\varepsilon p_{S}}\left(\frac{\sigma \pi+p_{T}-\varepsilon p_{S}}{(1-\varepsilon) p_{10}}\right)^{\kappa} \theta .
$$

(5) Energy equation

\section{1) Kinetic energy}

$$
\begin{aligned}
S t: \quad \frac{\partial}{\partial t} & \left(p_{T} K\right)+\nabla \cdot\left(p_{T} K \boldsymbol{V}+p_{T} \phi \boldsymbol{V}\right) \\
& +\frac{\partial}{\partial \sigma}\left(p_{T} K \dot{\boldsymbol{\sigma}}+p_{T} \phi \dot{\boldsymbol{\sigma}}\right)+\frac{\partial(\sigma \phi)}{\partial \sigma} \frac{\partial p_{T}}{\partial t} \\
& +p_{T} \omega \alpha=p_{T} \boldsymbol{V} \boldsymbol{F},
\end{aligned}
$$

where $K=\frac{1}{2} \boldsymbol{V}^{2}$ and $\alpha=-\left(\varepsilon / p_{T}\right)(\partial \phi / \partial \sigma)$ is a specific volume.

$$
\begin{aligned}
\operatorname{Tr}: \frac{\partial}{\partial t} & (\pi K)+\nabla \cdot(\pi K \boldsymbol{V}+\pi \phi \boldsymbol{V}) \\
& +\frac{\partial}{\partial \sigma}(\pi K \dot{\sigma}+\pi \phi \dot{\sigma})+\frac{\partial(\sigma \phi)}{\partial \sigma} \frac{\partial \pi}{\partial t}+\pi \omega \alpha \\
& +\left(\frac{\partial \phi}{\partial \sigma}\right) \frac{\partial}{\partial t}\left(p_{T}-\varepsilon p_{S}\right)=\pi \boldsymbol{V} \cdot \boldsymbol{F},
\end{aligned}
$$

where $\alpha=-((1-\varepsilon) / \pi)(\partial \phi / \partial \sigma)$.

\section{2) Potential energy}

$$
\begin{aligned}
S t: \quad \frac{\partial}{\partial t} & \left(p_{T} c_{p} T\right)+\nabla \cdot\left(p_{T} c_{p} T \boldsymbol{V}\right) \\
& +\frac{\partial}{\partial \sigma}\left(p_{T} c_{p} T \dot{\boldsymbol{\sigma}}\right)-p_{T} \omega \alpha=p_{T} \frac{d Q}{d t},
\end{aligned}
$$

$$
\begin{aligned}
& \text { Tr: } \frac{\partial}{\partial t}\left(\pi c_{p} T\right)+\nabla \cdot\left(\pi c_{p} T \boldsymbol{V}\right) \\
& \quad+\frac{\partial}{\partial \sigma}\left(\pi c_{p} T \dot{\sigma}\right)-\pi \omega \alpha=\pi \frac{d Q}{d t} .
\end{aligned}
$$

(6) Total energy equations

Integration of energy equations for total mass in the stratosphere and the troposphere leads to, under the assumption of vanishing of energy transfer at the lateral boundary,

$S t: \quad \frac{\partial}{\partial t} \int \frac{1}{\varepsilon g} p_{T} K d V=-\int \frac{1}{g} \phi_{T} \frac{\partial p_{T}}{\partial t} d S$

$$
-\int \frac{1}{\varepsilon g} p_{T} \omega \alpha d V+\int \frac{1}{\varepsilon g} p_{T} \boldsymbol{V} \cdot \boldsymbol{F} d V,
$$

$\operatorname{Tr}: \frac{\partial}{\partial t} \int \frac{1}{(1-\varepsilon) g} \pi K d V$

$$
\begin{aligned}
= & \int \frac{1}{g}\left(\phi_{T} \frac{\partial p_{T}}{\partial t}-\phi_{S} \frac{\partial p_{S}}{\partial t}\right) d S \\
& -\int \frac{1}{(1-\varepsilon) g} \pi \omega \alpha d V \\
& +\int \frac{1}{(1-\varepsilon) g} \pi \boldsymbol{V} \cdot \boldsymbol{F} d V,
\end{aligned}
$$

$S t: \quad \frac{\partial}{\partial t} \int \frac{1}{\varepsilon g} p_{T} c_{p} T d V=\int \frac{1}{\varepsilon g} p_{T} \omega \alpha d V$

$$
+\int \frac{1}{\varepsilon g} p_{T} \frac{d Q}{d t} d V
$$

$\operatorname{Tr}: \frac{\partial}{\partial t} \int \frac{1}{(1-\varepsilon) g} \pi c_{p} T d V$

$$
=\int \frac{1}{(1-\varepsilon) g} \pi \omega \alpha d V
$$




$$
+\int \frac{1}{(1-\varepsilon) g} \pi \frac{d Q}{d t} d V
$$

where $\int(\quad) d V \equiv \int(\quad) d x d y d \sigma$ and $\int(\quad) d S$ $\equiv \int(\quad) d x d y$ and the assumption that $\dot{\sigma}_{T}=0$ at $\sigma=\varepsilon$ is used.

Needless to say, terms including $\omega \alpha$ play roles in the exchange between kinetic and potential energies, and $\left(\phi_{T} / g\right)\left(\partial p_{T} / \partial t\right)$ and $\left(\phi_{S} / g\right)$ $\left(\partial p_{S} / \partial t\right)$ are related to the exchange of energy between the upper and the lower layers around the tropopause and the ground surface respectively. As we can easily see from (3.2), the term $\left(\phi_{T} / g\right)\left(\partial p_{T} / \partial t\right)$ is a part of the kinetic energy transfer, $(\omega \phi) / g$ at the tropopause in the $x, y, p$-system. Thus, we may say that the variation of $p_{T}$ with time, $\partial p_{T} / \partial t$, contributes to the kinetic energy transfer through the tropopause, which will be shown in the next section. At the same time, the presence of the pressure change with time or $\omega$ at the tropopause is identical with the fact that the vertical mean divergence in the troposphere does not vanish. In this meaning, the nonzero $\partial p_{T} / \partial t$ acts just like as an anchor or block for the spurious westward retrogression of the ultra-long waves.

\section{Kinetic energy transfer through the tropopause}

The energy transfer through the tropopause was investigated theoretically by Charney and Drazin (1961). With the use of an atmospheric model depicted here, let us examine the transfer of energy in more detail. We separate $\overline{\phi_{T}\left(\partial p_{T} / \partial t\right)}$ into two parts, i.e., $\bar{\phi}_{T}\left(\partial p_{T} / \partial t\right)$ and $\bar{\phi}_{T}^{\prime}\left(\partial p_{T}^{\prime} / \partial t\right)$, where bar denotes space mean at $\sigma=\sigma_{T}$ and primed quantity is the deviation from its average. If we take the area sufficiently large, $\left(\overline{\partial p_{T} / \partial t}\right)$ becomes almost zero. $\overline{\phi_{T}{ }^{\prime}\left(\partial p_{T}{ }^{\prime} / \partial t\right)}$ has close connection with the motion of tropospheric disturbances. Namely, when cyclone in the troposphere develops, the height of the tropopause associated with the trough tends to lower and accordingly the pressure at the tropopause increases. In the case of development of anticyclone like formation of blocking situation, almost inverse tend ency is oberved. Since these observational facts indicate a negative correlation between $\phi_{T}{ }^{\prime}$ and $\partial p_{T}{ }^{\prime} / \partial t$, it may be said from (3.10) that kinetic energy is transferred from the troposphere toward the stratosphere; that is, the troposphere acts as an energy source to the stratosphere, when large scale troughs or ridges develop. Fig. 2 illustrates the schematic relation of $\phi_{T}{ }^{\prime}$ and $\partial p_{T}{ }^{\prime} / \partial t$ which can be expressed as

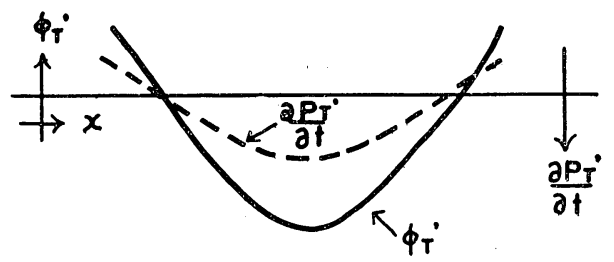

(a)

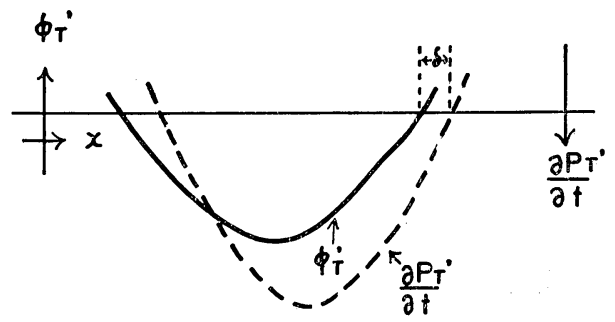

(b)
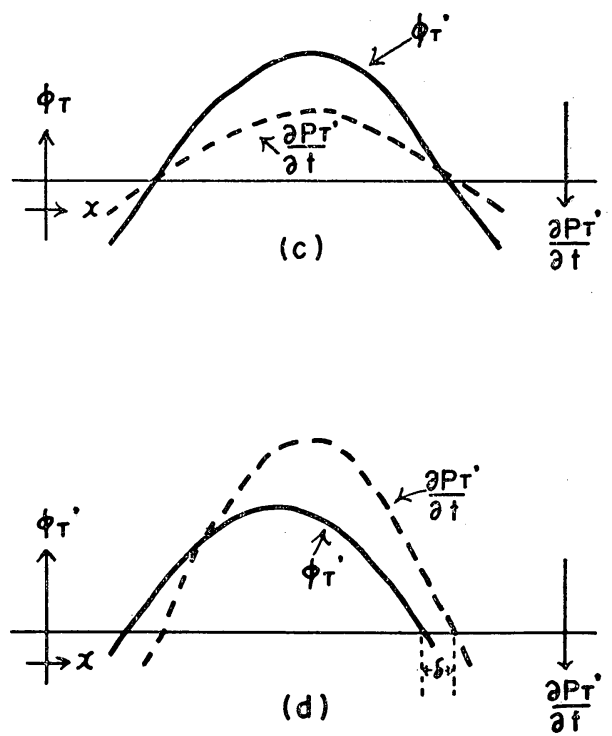

Fig. 2. Schematic configuration of $\phi_{T}{ }^{\prime}$ and $\partial p_{T}^{\prime} / \partial t$ in sinusoidal pattern. 


$$
\begin{gathered}
\phi_{T}{ }^{\prime}=A \sin k x, \quad(A>0), \\
\frac{\partial p_{T}{ }^{\prime}}{\partial t}=-B \sin k(x-\delta), \quad(B>0) .
\end{gathered}
$$

Hence

$$
\phi_{T}^{\prime} \frac{\partial p_{T}^{\prime}}{\partial t}=-C \Omega
$$

where $C=A B$ and $\Omega=\cos k \delta-\cos k(2 x-\delta)$.

(i) The case of trough $(\pi \leq k x \leq 2 \pi)$

Occlusion: $\delta \sim 0$ and $\Omega(>0)$ is large. $A(>0)$ is maximum but $B(>0)$ becomes small and then changes sign (i.e., upward and then downward transports). (Fig. 2a)

Development of migrating trough: $\delta \neq 0$ and $\Omega(>0)$ decreases. Both $A(>0)$ and $B(>0)$ increase (i.e., upward transport). (Fig. 2b). Hence, considering the fact that a short wave moves in general more rapidly than a long wave, and thus $\Omega$ and $C$ of the former are smaller than those of the latter, we can im- agine that the amplifying long wave, especially stationary wave, plays more important role on the strato-tropospheric interaction than the short wave.

(ii) The case of ridge $(0 \leq k x \leq \pi)$

Blocking: $\delta \sim 0$ and $\Omega(>0)$ is large. $A(>0)$ is maximum but becomes small and afterwards changes sign (i.e., upward and afterwards downward transfer). (Fig. 2c).

Formative stage of blocking or amplification of moving ridge: $\delta \neq 0$ and $\Omega(>0)$ is small. Both $A(>0)$ and $B(>0)$ increase (i.e., upward transfer). (Fig. 2d).

\section{Numerical estimation of the energy trans- fer}

Using the results of the aerological study of Defant and Taba (1958), we computed the correlation of $\phi_{T}{ }^{\prime}$ or $p_{T}{ }^{\prime}$ and $\partial p_{T}{ }^{\prime} \mid \partial t \simeq \Delta p_{T}{ }^{\prime} / \Delta t$. In Fig. 3 shown are the profiles of pressure at the tropopause and their time changes for 24 hours along a specified latitudinal arc. The
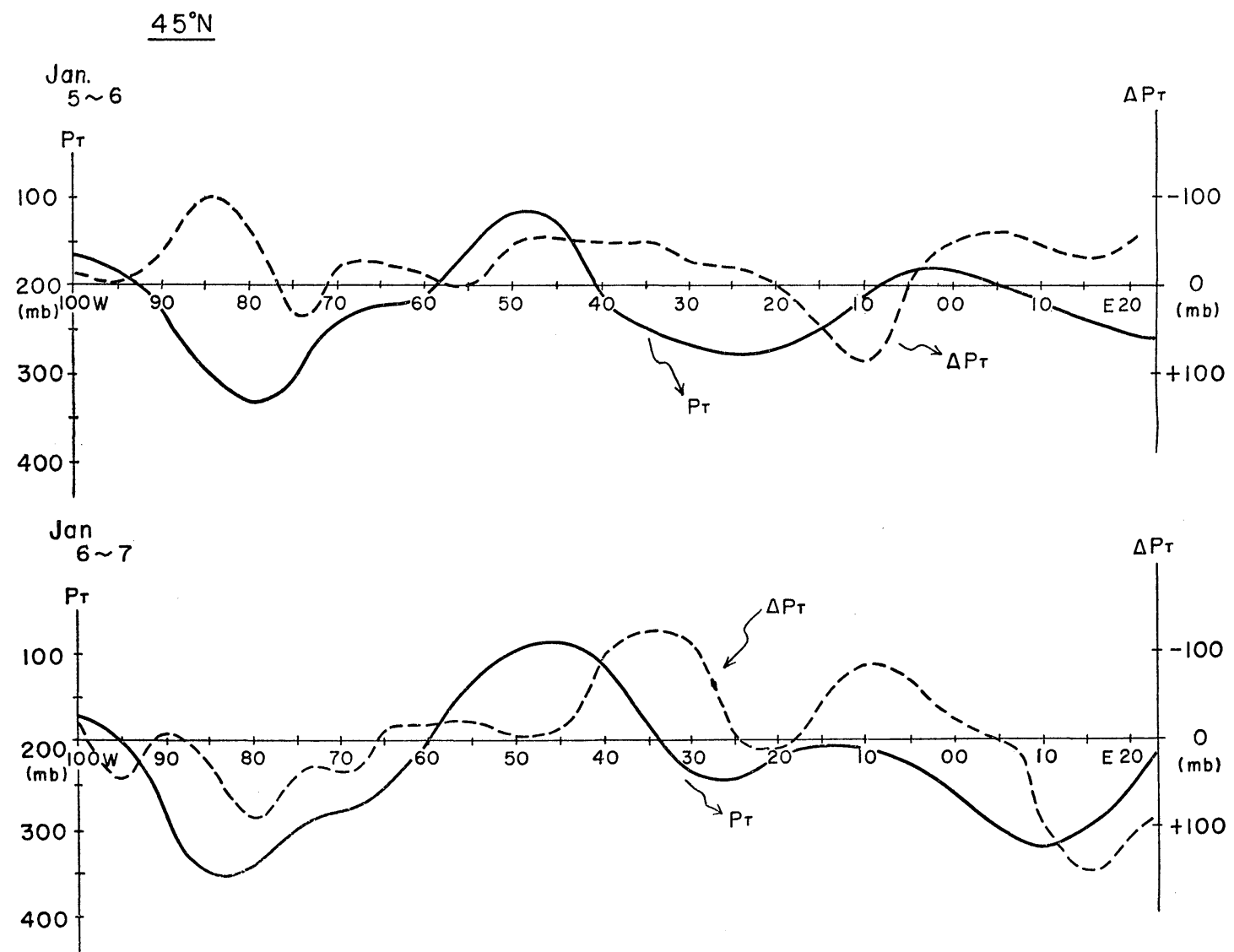

Fig. 3a. 

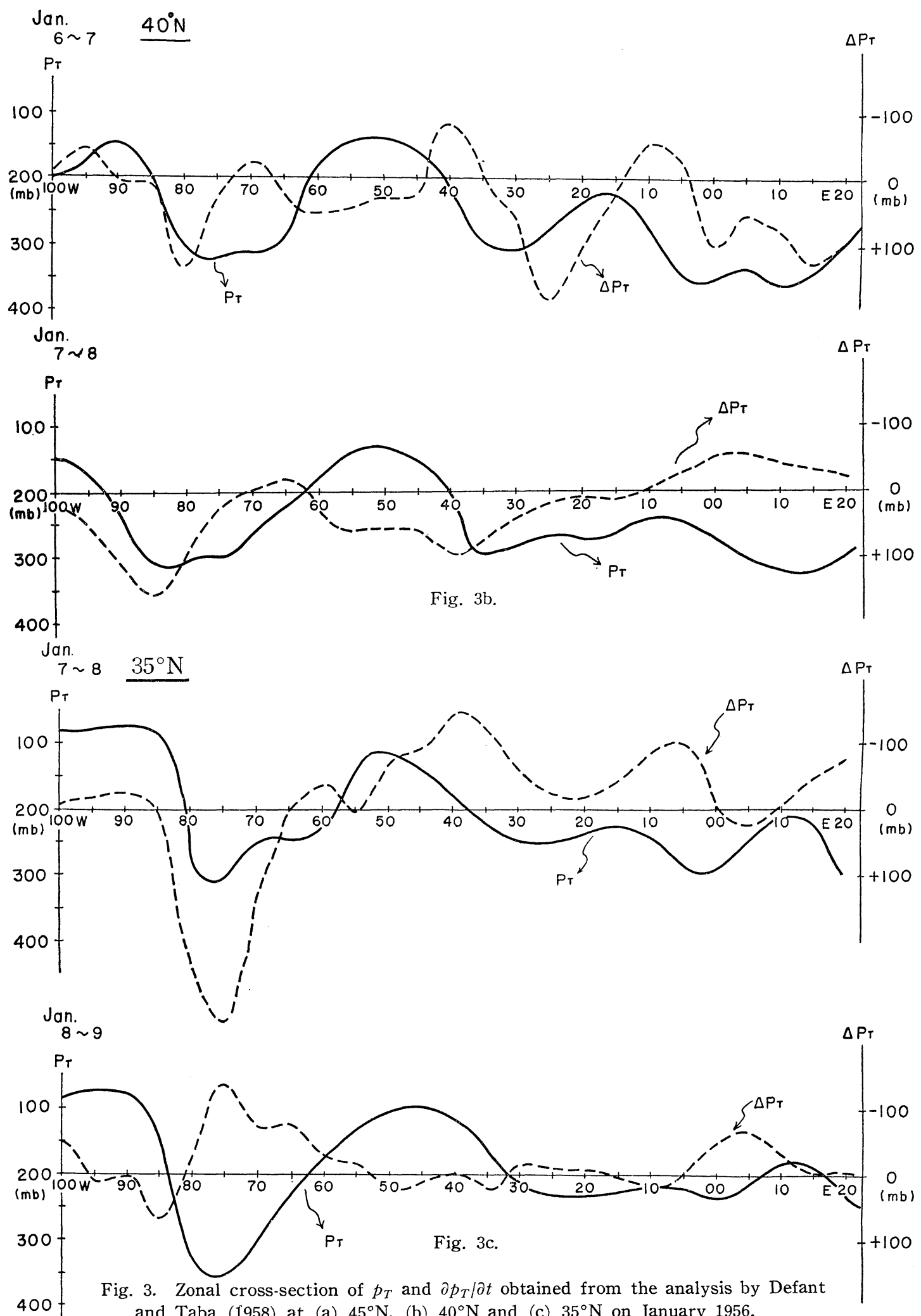

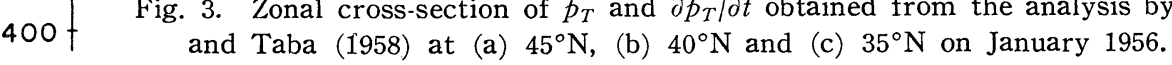


former are interpolated, by consideration of the movement of disturbances, from two successive maps of the tropopause pattern illustrated by Defant and Taba. The latter are computed as the difference between two successive profiles of $p_{T}$. Figs. $3 \mathrm{a}, \mathrm{b}, \mathrm{c}$ are zonal crosssections at $45^{\circ}, 40^{\circ}$ and $35^{\circ} \mathrm{N}$, for the datès from 5-6 January, 1956 in (a) to $8-9$ in (c). Thus, we can follow the profiles of $p_{T}$ and $\Delta p_{T}$ with time. The trough near $80^{\circ} \mathrm{W}$ begins to develop on 6-7 January and moves to southeastwards at the speed of about $5^{\circ}$ lat. per day. On 8-9 January, the development ceases and tends to decay. The assumption that the tropopause is a material surface and it has a constant value of potential temperature seems to be almost valid so far as this example is concerned. (Defant and Taba, 1957).

Table 1. Examples of the correlation $\left(\phi_{T}{ }^{\prime} / g\right) \partial p_{T}{ }^{\prime} / \partial t$ $\simeq\left(\phi_{T}^{\prime} / g\right) \Delta p_{T}^{\prime} / \Delta t$ calculated from the profiles of $p_{T}$ and $\Delta p_{T}$ illustrated in Fig. 3 after Defant and Taba (1958). Minus sign shows upward propagation and plus sign downward. (Unit: joule $\mathrm{m}^{-2} \mathrm{sec}^{-1}$ )

\begin{tabular}{l|r|r|r|r|r}
\hline & Jan. 5-6 & $6-7$ & $7-8$ & $8-9$ & Mean \\
\hline $45^{\circ} \mathrm{N}$ & 4.3 & -94.8 & & & -45.3 \\
40 & & -56.7 & -29.3 & & -43.0 \\
35 & & & -83.9 & 65.7 & -9.1 \\
\hline
\end{tabular}

In Table 1, given is the numerical value of the vertical propagation of kinetic energy through the tropopause, which is calculated from Fig. 3 and averaged along latitudinal arc. Computation was carried out with gridinterval of 5 degree longitude. We can presume from this result that the correlation $\mid \overline{p_{T}{ }^{\prime} \cdot\left(\partial p_{T}{ }^{\prime} / \partial t\right) \mid}$ has large values at developing stage, and that as soon as deepening stops, the correlation coefficient becomes small or sometimes even the sign changes. It is noted that the magnitude of the propagation of kinetic energy in vertical is of the order of 10 joule $\mathrm{m}^{-2} \mathrm{sec}^{-1}$, but it often changes its sign. The time mean value may be in the order of 1 joule $\mathrm{m}^{-2} \mathrm{sec}^{-1}$.

So far as the short term variation of an atmospheric motion is concerned, the interaction of kinetic energy between the troposphere and the lower stratosphere is rather active and the direction of energy propagation in vertical changes frequently. We can, however, say nothing, from these limited informations, about the long term features of the propagation and of the interaction between the troposphere and the stratosphere.

\section{Dynamical aspects of the tropospheric motion under the variable tropopause with special emphasis on very long wave}

In numerical prediction with a quasi-geostrophic model in $p$-coordinate we usually pose the following boundary conditions in vertical, i.e.,

$$
\omega=0 \text { at } p=p_{U} \text { and } p_{L},
$$

where $p_{U}$ and $p_{L}$ refer to pressure at the top and the lowest levels of the atmosphere, and the effect of orography is disregarded. When this method is used with a rough vertical resolution, one can not expect to include successfully an interaction of the troposphere and the layer above it. That is because the vertical mean divergence vanishes mostly in the troposphere. Because of this difficulty such an atmospheric model in $p$-system fails to describe accurately the motion of the ultralong wave and induces very rapid westward spurious movement as the result of the socalled $\beta$-effect. To avoid this shortcoming an artificial non-vanishing mean divergence was introduced in the model. (Cressman, 1958; Wiin-Nielsen, 1959).

Concerning these points, the atmospheric model mentioned in the preceding section is the one which is favorable to avoid the difficulty and is probably capable of simulating the real situation even with a coarse vertical resolution. To see these circumstances in more detail, let us solve the perturbation solution superposed on a zonal current in barotropic and baroclinic atmosphere incorporating the existence of the tropopause.

\section{(1) Equivalent barotropic model}

We shall in the following make an assumption for the vertical distribution of height $Z$ :

$$
\bar{Z}(x, y, p, t)=Z_{0}(p)+A(p) \cdot \bar{Z}(x, y, t),
$$

where

$$
\begin{gathered}
Z_{0}(p)=\frac{T_{0}}{\Gamma}\left[1-\left(\frac{p}{p_{0}}\right)^{R \Gamma / g}\right], \\
A(p)=a_{1} p^{2}+a_{2} p+a_{3},
\end{gathered}
$$




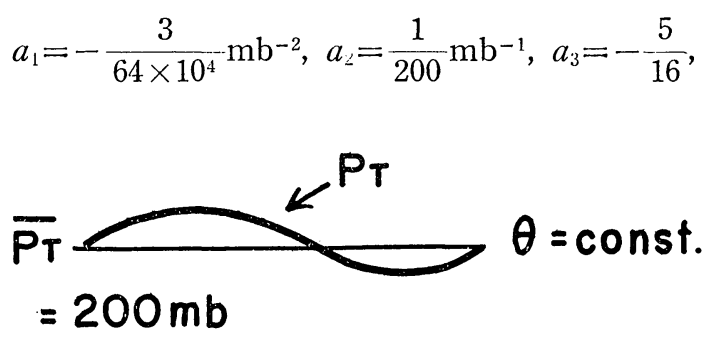

\section{$=1000 \mathrm{mb}$}

\section{Po}

Fig. 4. Vertical resolution in a barotropic model.

$T_{0}$ is the temperature at the ground surface $\left(288^{\circ} \mathrm{K}\right), \Gamma$ is the constant lapse rate $\left(0.65^{\circ} \mathrm{C} /\right.$ $100 \mathrm{~m})$, and $A(p)$ becomes 0 at $p=p_{0}=1000 \mathrm{mb}$, 1.0 at $p=p_{0}-\left(p_{0}-\bar{p}_{T}\right) / 2=600 \mathrm{mb}$ and 0.5 at $p=\bar{p}_{T}=200 \mathrm{mb}$ (Fig. 4). The functional form of $A(p)$ mentioned above is determined by the observed values of disturbance in the troposphere, this form may not be adequate for the basic zonal flow, but for the sake of simplicity we use the same formula of $A(p)$ both for the disturbance and the zonal current, since the form of $A(p)$ for the zonal flow is not essential here.

Thus, we can get the vertical distribution of potential temperature $\theta$ from (6.1) as

$$
\begin{gathered}
\theta(x, y, p, t)=\frac{g p}{R}\left(\frac{p_{0}}{p}\right)^{\kappa}\left[\frac{R T_{0}}{g p_{0}}\left(\frac{p}{p_{0}}\right)^{R \Gamma / g-1}\right. \\
\left.-\left(2 a_{1} p+a_{2}\right) \bar{Z}(x, y, t)\right] .
\end{gathered}
$$

Since we consider the tropopause as a material surface, $\theta=\theta_{T}=$ constant at $p=p_{T}$, where $p_{T}$ is the pressure distribution at the tropopause. For the sake of simplicity, we assume that

$$
\left.p_{T}(x, y, t)=\bar{p}_{T} \text { (=const. }\right)+p_{T}{ }^{\prime}(x, y, t) \text {. }
$$

Inserting $\theta=\theta_{T}$ and $p=p_{T}$ in (6.2) and using an inequality $\left|p_{T}{ }^{\prime}\right| \bar{p}_{T} \mid<1$, we have the first approximation for $p_{T}{ }^{\prime}(x, y, t)$, after expanding (6.2) with $p_{T}^{\prime} \mid \bar{p}_{T}$ and ignoring higher order terms, as follows.
$p_{T}{ }^{\prime}=\frac{\bar{p}_{T}\left[b_{1}-b_{2}{ }^{\prime}-b_{3} \bar{p}_{T} \cdot \bar{Z}(x, y, t)\right]}{\left[b_{1}(1-\kappa)+b_{2}\left(\frac{R I}{g}-1\right)-2 a_{1} \bar{p}_{T}^{2} \cdot \bar{Z}(x, y, t)\right]}$,

where

$$
\begin{gathered}
b_{1}=\frac{R \bar{T}_{T}}{g}, \bar{T}_{T}=\theta_{T}\left(\frac{\bar{p}_{T}}{p_{0}}\right)^{\kappa} \sim 216^{\circ} \mathrm{K}, b_{2}=\frac{R T_{0}}{g}, \\
b_{2}{ }^{\prime}=b_{2}\left(\frac{\bar{p}_{T}}{p_{0}}\right)^{R \Gamma^{\prime g} g}, \text { and } b_{3}=-\left(2 a_{1} \bar{p}_{T}+a_{2}\right) .
\end{gathered}
$$

As an amplitude of pressure at the tropopause is not so small compared with $\bar{p}_{T}$ itself, the inequality is more or less crude but the essential characteristics would still be kept. If we disregard the existence of tropopause, i.e., $\theta_{T} \rightarrow \infty$, (6.3) states that $p_{T}{ }^{\prime}$ must vanish.

From the assumption that the tropopause is material, it follows that an air parcel should not depart from the surface; in other words, $\dot{\sigma}=0$ at $p=p_{T}$. We thus have

$$
\omega_{T}=\frac{\partial p_{T}{ }^{\prime}}{\partial t}+V_{T} \cdot \nabla p_{T}{ }^{\prime}
$$

Now, let us consider the quasi-geostrophic vorticity equation in $p$-system which reads

$$
\frac{\partial \zeta_{g}}{\partial t}+V_{g} \cdot \nabla\left(\zeta_{g}+f\right)-f_{0} \frac{\partial \omega}{\partial p}=0,
$$

where $\zeta_{g}=\left(g / f_{0}\right) \nabla^{2} Z(x, y, p, t)$. In the following, we put $f=f_{0}+\beta y$. $f_{0}$ is Coriolis parameter at $45^{\circ} \mathrm{N}$ and $\beta=\partial f / \partial y$ is assumed to be constant. It is known that assumption of $\beta$ plane becomes inaccurate as wave length tends to increase. Nevertheless we use it here for the sake of simplicity, so that meridional wave length should be small.

Inserting (6.1) into (6.5), integrating with respect to pressure from $p_{T}$ to $p_{0}$ and linearizing under the assumption that

$$
\bar{Z}(x, y, t)=\bar{Z}_{D}(x, t)-\frac{g}{f_{0}} \bar{U} y,
$$

we get

$$
\begin{aligned}
& d_{1}\left(\frac{\partial}{\partial t} \frac{\partial^{2}}{\partial x^{2}}+\beta \frac{\partial}{\partial x}\right) \bar{Z}_{D}+d_{2} \bar{U} \frac{\partial}{\partial x} \frac{\partial^{2}}{\partial x^{2}} \bar{Z}_{D} \\
& \quad+d_{3} \frac{\partial \vec{Z}_{D}}{\partial x}+f_{0} \omega_{T}=0,
\end{aligned}
$$

where $d_{1}, d_{2}$ and $d_{3}$ are combinations of $a_{1}$, 
$a_{2}, a_{3}, p_{0}, p_{T}, g, f_{0}$ and $\partial \bar{p}_{T} / \partial y$ (see Appendix A).

From (6.3) and (6.4), we get

$$
\begin{aligned}
\omega_{T} & =\left(\frac{\partial}{\partial t}+\frac{1}{2} \bar{U} \frac{\partial}{\partial x}\right) p_{T}{ }^{\prime} \\
& =-\nu\left(\frac{\partial}{\partial t}+\frac{1}{2} \bar{U} \cdot \frac{\partial}{\partial x}\right) \bar{Z}_{D},
\end{aligned}
$$

where $\nu$ is approximately $0.28 \mathrm{mb} / \mathrm{m}$ for parameters adopted here and we ignored the third term in the denominator of (6.3) considering an average state.

Therefore we finally have the following prognostic equation for the equivalent barotropic model from (6.6) and (6.7).

$$
\begin{aligned}
& \left(\frac{\partial^{2}}{\partial x^{2}}-\mu^{2}\right) \frac{\partial}{\partial t} \bar{Z}_{D}+\left(\beta+\gamma-\frac{\bar{U}}{2} \mu^{2}\right) \frac{\partial}{\partial x} \bar{Z}_{D} \\
& \quad+\bar{U}^{*} \frac{\partial^{3}}{\partial x^{3}} \bar{Z}_{D}=0
\end{aligned}
$$

where $\mu^{2}=\left(f_{0} / d_{1}\right) \nu \simeq 0.47 \times 10^{-12} \mathrm{~m}^{-2}, \quad \gamma=d_{3} / d_{1}$ $=(1 / 600) \cdot\left(f_{0} / 2\right) \cdot\left(\partial \bar{p}_{T} / \partial y\right) \sim 0\left(10^{-12}\right)$ in M. Gr. Sec. unit and $\bar{U}^{*}=\left(d_{2} / d_{1}\right) \bar{U} \simeq(2 / 3) \bar{U}$.

Equation (6.8) may be satisfied by a trigonometric wave solution of the form: $\bar{Z}_{D} \sim \exp$ $i k(x-C t)$, provided

$$
C=\frac{\bar{U} * k^{2}+\frac{\bar{U}}{2} \mu^{2}-\beta-\gamma}{k^{2}+\mu^{2}}=\frac{\bar{U}^{*}+\frac{\bar{U}}{2} \frac{\mu^{2}}{k^{2}}-\frac{\beta}{k^{2}}-\frac{\gamma}{k^{2}}}{1+\mu^{2} / k^{2}}
$$

and $k=2 \pi / L$ ( $L$ is a wave length).

Except additional terms in the numerator, the formula of the phase velocity obtained here has the similar form to that may be available when we give an artificial mean divergence in the vorticity equation described in $p$-coordinate by Wiin-Nielsen (1959). Physical implications are, however, somewhat different from each other. We have not so far made any assumption about the vertical distribution of static stability in the troposphere as Wiin-Nielsen did, but we have taken into account the variation of the tropopause pressure. In other words, the motion of the ultralong wave was treated in a self-adjusting system of the interaction between the stable stratosphere and the troposphere. The feasibility of the vertical transfer of kinetic energy through the tropopause simultaneously results in the non-vanishing vertical mean divergence in the troposphere, which is indirectly controled by the vertical distributions of static stability in both the stratosphere and the troposphere.

Mean meridional northward inclination of the tropopause pressure $\partial \bar{p}_{T} / \hat{\partial} y$ acts just like as $\beta$-effect on phase speed of disturbance but $\gamma$ seems to be less by one order of magnitude than $\beta$ for the characteristic value of $\partial \bar{p}_{T} / \partial y$ in (6.9). As we can easily see in (6.9), phase speed $C$ becomes finite in the limit, $k \mapsto 0$ ( $L$ $\rightarrow \infty)$, i.e., $C=-\left(\beta+\gamma-U_{0} \mu^{2} / 2\right) / \mu^{2}$. But if we disregard the existence of tropopause and make $\mu^{2}$ to be zero, $C$ becomes infinite and there will appear the rapid retrogression or the false westward movement of the very long wave.

\section{(2) 2-level baroclinic model}

Under the incorporation of a self-adjusting control of the ultra-long waves in a way similar to the one used in the barotropic case treated in the preceding section, we shall next solve the perturbation equations for the simple baroclinic model and observe whether or not the existence of the tropopause changes the phase velocity of disturbance and/or the instability criterion.
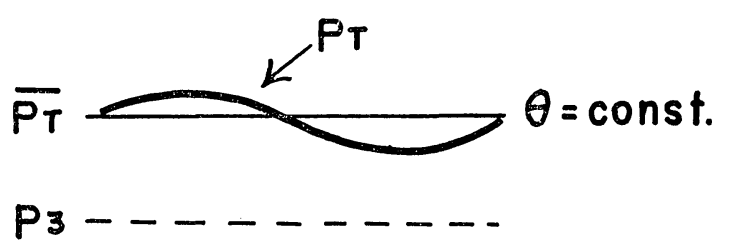

\section{$P_{4}$}

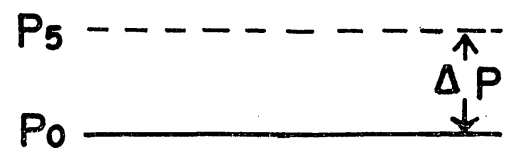

Fig. 5. Vertical resolution in a baroclinic model.

For the sake of simplicity we shall again assume that the tropopause pressure $p_{T}$ may be expressed as $\bar{p}_{T}+p_{T}{ }^{\prime}$, where $\bar{p}_{T}$ is constant and $p_{T}{ }^{\prime}=p_{T}{ }^{\prime}(x, y, t)$, and a vertical $p$-velocity at $p=\bar{p}_{T}$ may be equal to $\omega_{T}$ in (6.7). These assumptions are rather crude but do not distort the essential feature of the present dis- 
cussion. $\quad \bar{p}_{T}=200, p_{3}=400, p_{4}=600, p_{5}=800$ and $p_{0}=1000 \mathrm{mb}$ surfaces are denoted with subscripts $T, 3,4,5$ and 0 .

The vorticity equation for the mean flow $Z_{m}=\left(Z_{3}+Z_{5}\right) / 2$ and the shear flow $Z_{S}=\left(Z_{3}-Z_{5}\right) /$ 2 , and the thermal equation for level 4 may read

$$
\left(\frac{\partial}{\partial t}+V_{m} \cdot \nabla\right) \zeta_{m}+V_{S} \cdot \nabla \zeta_{S}+\beta v_{m}+\frac{f_{0}{ }^{2}}{2 \Delta p \cdot g} \omega_{T}=0
$$

$$
\begin{gathered}
\left(\frac{\partial}{\partial t}+\boldsymbol{V}_{m} \cdot \nabla\right) \zeta_{S}+\boldsymbol{V}_{S} \cdot \nabla \zeta_{m}+\beta v_{S} \\
-\frac{f_{0}{ }^{2}}{\Delta p \cdot g} \omega_{4}+\frac{f_{0}{ }^{2}}{2 \Delta p \cdot g} \omega_{T}=0 \\
\omega_{4}=\frac{2 g}{S \Delta p}\left(\frac{\partial}{\partial t}+V_{m} \cdot \nabla\right) Z_{S}
\end{gathered}
$$

and $\omega_{T}=-\nu\left(\frac{\partial}{\partial t}+\frac{1}{2} V_{m} \cdot \nabla\right) Z_{m}$, where $U_{m}=\frac{1}{2}$ $\left(U_{3}+U_{5}\right), U_{S}=\frac{1}{2}\left(U_{3}-U_{5}\right), U_{4} \simeq U_{m}$ and $S$, the static stability, is constant.

Inserting wave solution into $(6.10)-(6.12)$ and linearizing them, we obtain the frequency determining equation (see Appendix B), which gives the phase speed as

$$
\begin{aligned}
C= & \frac{2+1 \frac{1}{2} \frac{\mu^{2}}{k^{2}}}{2\left(1+\mu^{2} / k^{2}\right)} U_{m}-\frac{2+\frac{\mu^{2}}{k^{2}}+\frac{\varepsilon}{k^{2}}}{2\left(1+\mu^{2} / k^{2}\right)\left(1+\varepsilon / k^{2}\right)} \frac{\beta}{k^{2}} \\
& -\frac{\frac{k^{2}}{k^{2}}}{2\left(1+\mu^{2} / k^{2}\right)\left(1+\varepsilon / k^{2}\right)} U_{S} \\
& \pm \frac{\sqrt{D}}{2\left(1+\mu^{2} / k^{2}\right)\left(1+\varepsilon / k^{2}\right)},
\end{aligned}
$$

where

$$
\begin{aligned}
D= & {\left[\frac{1}{2}\left(\frac{\mu^{2}}{k^{2}}\right)\left(1+\frac{\varepsilon}{k^{2}}\right) U_{m}+\left(\varepsilon-\mu^{2}\right) \frac{\beta}{k^{4}}\right]^{2} } \\
& -4 U_{S}{ }^{2}\left(1+\frac{\mu^{2}}{k^{2}}\right)\left(\left(\frac{\varepsilon}{k^{2}}\right)^{2}-1\right) \\
& -2\left(1+\frac{\varepsilon}{k^{2}}\right)\left(\frac{\mu^{2}}{k^{2}}\right)\left(1+\frac{1}{2} \frac{\mu^{2}}{k^{2}}\right) U_{m} U_{S} \\
& +2 U_{S}\left(\frac{\mu^{2}}{k^{2}}\right)\left(\frac{\beta}{k^{2}}\right)\left[2+\left(\frac{\mu^{2}}{k^{2}}\right)+\left(\frac{\varepsilon}{k^{2}}\right)\right] \\
& +U_{S}{ }^{2}\left(\frac{\mu^{2}}{k^{2}}\right)^{2}, \\
& \varepsilon=\frac{2 f_{0}{ }^{2}}{S \Delta p^{2}}, \text { and } \mu^{2}=\nu f_{0}{ }^{2} /(2 \Delta p \cdot g) .
\end{aligned}
$$

In the case of $\omega_{T} \ll \omega_{4}$, we can ignore $\omega_{T}$ in (6.11) and then term including $U_{S}$ in (6.13) and the third, forth and fifth terms in the right hand side of (6.14) will disappear.

Again, results in the baroclinic case are formally parallel to those obtained in the case of artificial non-vanishing mean divergence, for example, solutions by Wiin-Nielsen (1959). Therefore we will briefly observe results. In (6.13), if we make $k \rightarrow 0 \quad(L \rightarrow \infty)$ to see how the phase velocity becomes for very long wave, we obtain

$$
\lim _{k \rightarrow 0} C=\left\{\begin{array}{l}
\frac{5}{4} U_{m}-\frac{\beta}{\varepsilon} \text { for plus sign, } \\
\frac{1}{4} U_{m}-\frac{\beta}{\mu^{2}} \text { for minus sign. }
\end{array}\right.
$$

It should be noted that in (6.16) the ultralong wave in the baroclinic case again has finite phase speed if the variation of tropopause pressure is incorporated. Appearance of $\frac{1}{4} U_{m}$ in (6.16) is not essential, for it depends on the functional form of $A(p)$.

For a baroclinic unstable wave, the assumption $\omega_{T} \ll \omega_{4}$ is permissible and the instability condition $D<0$ reduces to

$$
\begin{aligned}
& 4 U_{S}^{2}\left(1+\frac{\mu^{2}}{(2 \pi)^{2}} L^{2}\right)\left(\frac{\varepsilon^{2}}{(2 \pi)^{4}} L^{4}-1\right) \\
& >\left[\frac{1}{2}\left(\frac{\mu^{2}}{(2 \pi)^{2}} L^{2}\right)\left(1+\frac{\varepsilon}{(2 \pi)^{2}} L^{2}\right) U_{m}\right. \\
& \left.+\frac{\left(\varepsilon-\mu^{2}\right) \beta}{(2 \pi)^{4}} L^{4}\right]^{2}
\end{aligned}
$$

In the case of $\mu^{2}=0$, the mean zonal velocity $U_{m}$ is irrelevant of the instability condition. In order to satisfy $(6.17)$ the wave length of an unstable wave $L^{*}$ must be

$$
L^{*}>\frac{2 \pi}{\sqrt{ } \varepsilon},
$$

where for $S=2.5 \times 10^{-2} \mathrm{~m}^{2} \mathrm{sec}^{-2} \mathrm{mb}^{-2}, L^{*}=2810$ $\mathrm{km}$ and for $S=5 \times 10^{-2} \mathrm{~m}^{2} \mathrm{sec}^{-2} \mathrm{mb}^{-2}, L^{*}=3966$ $\mathrm{km}$.

From (6.17) we can see that,

(a) if $U_{m}$ happens to be zero,

(1) waves become unstable for smaller $U_{S}$ than for that of non-zero $U_{m}$ and

(2) for a fixed wave length, $U_{S}{ }^{*}$ which is the minimum wind shear necessary for 
baroclinic instability becomes smaller for $\mu^{2} \neq 0$ than that for $\mu^{2}=0$.

Also we observe that,

(b) if $\mu^{2} \neq 0$, the larger the value of $U_{m}$, the larger the value of $U_{S}{ }^{*}$ and that,

(c) if $\mu^{2}=0, U_{S} *$ is smaller than that for $\mu^{2} \neq 0$ for wave lengths less than a certain critical value which depends on $U_{m}$, on the other hand, for wave length beyond the critical value $U_{S}{ }^{*}$ is smaller in the case of $\iota^{2} \neq 0$ than that of $\mu^{2}=0$.

\section{Conclusions}

In order to incorporate the effect of the variable tropopause and of the stratosphere and to examine the influence on the motion of tropospheric disturbance, a computational atmospheric model is designed and its properties are investigated. The tropopause is treated as a material surface.

The energy equation shows that the vertical transfer of kinetic energy through the tropopause is expressed in the terms of $\left(\overline{\phi_{T}^{\prime}} / g\right)$. $\partial p_{T}^{\prime} / \partial t$ which makes it simple to estimate the transport of energy from observational data. Heuristic consideration on this term reveals that the amplifiying long wave, especially stationary wave, plays more important role in the strato-tropospheric interaction than the short wave.

Using aerological materials presented by Defant and Taba (1958), we computed $\left(\phi_{T}^{\prime} / g\right)$. $\bar{\partial} p_{T}^{\prime} / \partial t$. The results indicate strong interaction through kinetic energy between the troposphere and the stratosphere, though the term of computation is rather short.

$\sigma$-coordinate system is not convenient to treat in the form of vorticity and divergence equation and also complicated in the process of filtering meteorological noises. So we solved the quasi-geostrophic equations expressed with $p$-coordinate which retains the physical characteristics of $\sigma$-system, and obtained wave solutions of linearized forms of prognostic equations in the barotropic and baroclinic model. The resulting prognostic equations are formally similar to those obtained with respect to the equations of Cressman's model. This model contains the non-vanishing mean divergence and is favorable to suppress the westward sprious retrogression of the ultralong wave in the troposphere. The existence of the vertical transfer of kinetic energy through the tropopause is important because it is related to the non-vanishing vertical mean divergence in the troposphere, which is indirectly controled by the vertical distribution of static stability in both the stratosphere and the troposphere.

Hence we obtain the formula of the phase velocity of wave and curves of baroclinic instability which are modified by the existence of the stratosphere and similar to those obtained by Wiin-Nielsen (1959). Generally speaking the baroclinic instability criterion is shifted in the same sense as $\beta$-effect is weakened.

The numerical prediction model described in $\sigma$-coordinate system presented in this paper is favorable to take into account the variation of tropopause pressure and the existence of the stable stratosphere for forecasting the motion of the tropospheric disturbance.

\section{Acknowledgments}

The author wishes to express his hearty thanks to Prof. S. Syōno, Tokyo University, for his constant encouragement throughout this work. The author is also greatly indebted to Dr. A. Arakawa, Electronic Computation Center of Japan Meteorological Agency, for his very useful suggestions and constractive criticism, to staff members of our Center and particularly to Dr. K. Gambo for their kind encouragements.

It is a pleasure to thank Miss K. Endo for typewriting the manuscript and Miss Y. Atsuki for drafting figures.

\section{Appendix}

A. Derivation of the linearized equation (6.6)

Inserting (6.1) into (6.5) and integrating with respect to pressure from $p_{T}$ to $p_{0}$, we obtain

$$
\begin{aligned}
& \left(\frac{\partial \bar{\zeta}_{g}}{\partial t}+\left(\frac{\partial f}{\partial y}\right) \bar{v}_{g}\right) \int_{p_{T}}^{p_{0}} A(p) d p \\
& \quad+\left(\overline{\boldsymbol{V}}_{g} \cdot \nabla \bar{\zeta}_{g}\right) \int_{p_{T}}^{p_{0}} A^{2}(p) d p+f_{0} \omega_{T} \\
& \quad+A\left(p_{T}\right)\left(\bar{\zeta}_{g} \frac{\partial p_{T}}{\partial t}+\bar{v}_{g} f \frac{\partial p_{T}}{\partial y}\right) \\
& \quad+A^{2}\left(p_{T}\right)\left(\overline{\boldsymbol{V}}_{g} \cdot \bar{\zeta}_{g} \nabla p_{T}\right)=0
\end{aligned}
$$

where $\omega=0$ at $p=p_{0}$ is used. Although equation (5.7) is described in $p$-coordinate system, 
it includes the physical effect of the tropopause and is essentially equivalent to the vorticity equation for the large scale motion in $\sigma-$ coordinate system. If we linearize (A.1) under the assumption that

$$
\bar{Z}(x, y, t)=\bar{Z}_{D}(x, t)-\frac{g}{f_{0}} \bar{U}_{y},
$$

and take into account the functional form for $A(p),(\mathrm{A} .1)$ is reduced to (6.6), i.e.,

$$
\begin{aligned}
& d_{1}\left(\frac{\partial}{\partial t} \frac{\partial^{2}}{\partial x^{2}}+\beta \frac{\partial}{\partial x}\right) \bar{Z}_{D}+d_{2} \bar{U} \frac{\partial}{\partial x} \frac{\partial^{2}}{\partial x^{2}} \bar{Z}_{D} \\
& \quad+d_{3} \frac{\partial \bar{Z}_{D}}{\partial x}+f_{0} \omega_{T}=0
\end{aligned}
$$

where

$$
\begin{aligned}
d_{1}= & \frac{g}{f_{0}}\left[\frac{a_{1}}{3}\left(p_{0}{ }^{3}-\bar{p}_{T}{ }^{3}\right)+\frac{a_{2}}{2}\left(p_{0}{ }^{2}-\bar{p}_{T}{ }^{2}\right)\right. \\
& \left.+a_{3}\left(p_{0}-\bar{p}_{T}\right)\right] \simeq \frac{g}{f_{0}} \times 600 \mathrm{mb}, \\
d_{2}= & \frac{g}{f_{0}}\left[\frac{a_{1}^{2}}{5}\left(p_{0}{ }^{5}-\bar{p}_{T}{ }^{5}\right)+\frac{a_{1} a_{2}}{2}\left(p_{0}{ }^{4}-\bar{p}_{T}{ }^{4}\right)\right. \\
& +\frac{1}{3}\left(a_{2}{ }^{2}+2 a_{1} a_{3}\right)\left(p_{0}{ }^{3}-\bar{p}_{T}{ }^{3}\right)+a_{2} a_{3}\left(p_{0}{ }^{2}-\bar{p}_{T}{ }^{2}\right) \\
& \left.+a_{3}{ }^{2}\left(p_{0}-\bar{p}_{T}\right)\right] \simeq \frac{g}{f_{0}} \times 400 \mathrm{mb}, \\
d_{3}= & \frac{g}{f_{0}}\left(\frac{f_{0}}{2} \frac{\partial \bar{p}_{T}}{\partial y}\right) .
\end{aligned}
$$

B. Derivation of the frequency determining equation

Inserting wavy solution

$$
Z_{\text {in }}=-\frac{f_{0}}{g} U_{m} y+\hat{Z}_{m} e^{i k(x-c t)}
$$

and

$$
Z_{S}=-\frac{f_{0}}{g} U_{S} y+\hat{Z}_{S} e^{i k(x-C t+\delta)}
$$

into (6.10)-(6.12) and linearizing them, we obtain the frequency determining equation

$$
\begin{aligned}
& \left(1+\mu^{2} / k^{2}\right)\left(1+\varepsilon / k^{2}\right) C^{2}+\left[( 1 + \mu ^ { 2 } / k ^ { 2 } ) \left(\beta / k^{2}-U_{m}\right.\right. \\
& \left.-\left(\varepsilon / k^{2}\right) U_{m}\right)+\left(1+\varepsilon / k^{2}\right)\left(\beta / k^{2}-U_{m}-\left(\mu^{2} / 2 k^{2}\right) U_{m}\right) \\
& \left.+U_{S}\left(\mu^{2} / k^{2}\right)\right] C+\left[\left(\beta / k^{2}-U_{m}-\left(\mu^{2} / 2 k^{2}\right) U_{m}\right)\right. \\
& \quad \times\left(\beta / k^{2}-U_{m}-\left(\varepsilon / k^{2}\right) U_{m}\right)+U_{S}^{2}\left(\varepsilon / k^{2}-1\right) \\
& \left.-\left(U_{m} U_{S} / 2\right)\left(\mu^{2} / k^{2}\right)\right]=0 .
\end{aligned}
$$

C. Treatment of (6.10)-(6.12) as an initial value problem
It is of interest to treat $(6.10)-(6.12)$ as an initial value problem in a way similar to the one presented by Ogura (1957). Assuming the form of particular solution of $(6.10)-(6.12)$ as

$$
\begin{aligned}
& Z_{3}(x, y, t)=-\frac{f_{0}}{g} U_{3} y+\alpha_{3}(t) e^{i k x+i \delta_{3}(t)} \\
& Z_{5}(x, y, t)=-\frac{f_{0}}{g} U_{5} y+\alpha_{5}(t) e^{i k x+i \delta_{5}(t)}
\end{aligned}
$$

we can obtain the initial tendency for the amplification and the phase velocity at level 3 and 5 as follows.

$$
\begin{aligned}
& \frac{d \alpha_{3}}{d t}=-\frac{k \alpha_{5}}{(\gamma+2)\left(1+\mu^{*} / k^{2}\right)}\left[\frac{\beta}{k^{2}}+V-\left(\frac{\mu^{2}}{\varepsilon}\right)\right. \\
& \left.\times\left(\frac{\gamma+1}{\gamma} \frac{U_{m}}{2}+\frac{\beta}{k^{2}}-U_{5}-\frac{U_{3}}{\gamma}\right)\right] \\
& \times \sin \left(\delta_{5}-\delta_{3}\right) \text {, } \\
& C_{3}=-\frac{1}{k} \frac{d \delta_{3}}{d t}=\frac{U_{3}-\beta / k^{2}}{1+\mu^{*} / k^{2}}-\frac{1}{(\gamma+2)\left(1+\mu^{*} / k^{2}\right)} \\
& \times\left[V\left\{1+\frac{\alpha_{5}}{\alpha_{3}} \cos \left(\delta_{5}-\delta_{3}\right)\right\}\right. \\
& -\frac{\beta}{k^{2}}\left\{1-\frac{\alpha_{5}}{\alpha_{3}} \cos \left(\delta_{5}-\delta_{3}\right)\right\}-\left(\frac{\mu^{2}}{\varepsilon}\right) \\
& \times\left\{\left(\frac{\gamma+1}{\gamma} \frac{U_{m}}{2}+\frac{U_{5}}{\gamma}\right)+\frac{\alpha_{5}}{\alpha_{3}}\left(\frac{\gamma+1}{\gamma} \frac{U_{m}}{2}\right.\right. \\
& \left.\left.\left.+\frac{\beta}{k^{2}}-U_{5}-\frac{U_{3}}{\gamma}\right) \cos \left(\delta_{5}-\delta_{3}\right)\right\}\right] \text {, } \\
& \frac{d \alpha_{5}}{d t}=-\frac{k}{\gamma+2} \alpha_{3}\left[V-\frac{\beta}{k^{2}}+\frac{\mu^{2} / \varepsilon}{\gamma\left(1+\mu^{*} / k^{2}\right)}\right. \\
& \left.\times\left(\frac{U_{m}}{2}-U_{3}+\frac{\beta}{k^{2}}\right)\right] \sin \left(\delta_{5}-\delta_{3}\right), \\
& C_{5}=-\frac{1}{k} \frac{d \delta_{5}}{d t}=\frac{(\gamma+1)\left(1+\mu^{*} / k^{2}\right)+1}{(\gamma+2)\left(1+\mu^{*} / k^{2}\right)}\left(U_{5}-\frac{\beta}{k^{2}}\right) \\
& +\left[\left\{\left(\frac{U_{3}}{1+\mu^{*} / k^{2}}-U_{5}\right)+V \frac{\alpha_{3}}{\alpha_{5}} \cos \left(\delta_{3}-\delta_{5}\right)\right\}\right. \\
& +\frac{\beta}{k^{2}}\left\{1-\frac{\alpha_{3}}{\alpha_{5}} \cos \left(\delta_{3}-\delta_{5}\right)\right\}+\frac{\mu^{2} / \varepsilon}{\gamma\left(1+\mu^{*} / k^{2}\right)} \\
& \times\left\{\left(\frac{U_{m}}{2}-U_{3}\right)+\left(\frac{U_{m}}{2}-U_{3}+\frac{\beta}{k^{2}}\right)\right. \\
& \left.\left.\times \frac{\alpha_{3}}{\alpha_{5}} \cos \left(\delta_{3}-\delta_{5}\right)\right\}\right] \text {, }
\end{aligned}
$$

where $\mu^{*}=\mu^{2} / 2, \mu^{2}=\nu f_{0}{ }^{2} /(2 \Delta p \cdot g), \varepsilon=2 f_{0}{ }^{2} /\left(S \Delta p^{2}\right)$, $\gamma=2 k^{2} / \varepsilon$ and $V=U_{3}-U_{5}$. If $\mu^{2}=0$, (C. 3 ) and (C. 4) become the same as those derived by 
Ogura. In barotropic cace, i.e., $\gamma \rightarrow \infty$, we get

$$
\frac{d \alpha_{3}}{d t}=0
$$

and

$$
C_{3}=\frac{U_{3}-\beta / k^{2}}{1+\mu^{*} / k^{2}}
$$

The latter is same as (6.9). Equation (C. 3) and (C.4) state that the initial tendency for the amplification at upper level is reduced by a factor $\mu^{*} / k^{2}(>0)$ in the denominator, but at lower level the effect of $\mu^{*} / k^{2}$ varies and decreases. Physical interpretation of baroclinicity appeared in (C. 3$)-($ C. 6$)$ may not be needed to be explained here. Concerning the phase speed, control of the very long wave at upper level is clearly shown in (C. 4) but, at lower level, we observe in (C. 6) that control is not enough at least as far as the initial trend is concerned. As to the mean phase velocity in the whole troposphere, the control of ultra-long wave can be performed as is shown in (6.16). In our analytical argument we have disregarded the pressure change with respect to time on the ground surface since the magnitude of the change is smaller than that at tropopause. In the exact treatment of $\sigma$-system, this pressure variation on the ground should be incorporated and may contribute to suppress the false retrogression, especially in the lower part of the troposphere.

\section{References}

Burger, A.P., 1958: Scale consideration of plane- tary motions of the atmosphere. Tellus, 10, 196-205.

Charney, J.G. and P.G. Drazin, 1961: Propagation of planetary-scale disturbances from the lower into the upper atmosphere. J. geophys. Res., 66, 83-109.

Cressman, G.P., 1958: Barotropic divergence and very long atmospheric waves. Mon. Wea. Rev., 86, 293--297.

Eliassen, A., 1960: On the use of a material layer model of the atmosphere in numerical prediction. Proceedings of international symposium on numerical weather prediction in Tokyo. 207-212.

Gates, W.L., 1957: A dynamical model for largescale tropospheric and stratospheric motions. Quart. J. Roy. meteor. Soc., 83, 141-160.

Murakami, T., 1964: Multiple-level model for the $p$ - and $s$-coordinates. J. meteor. Soc. Japan, $42,1-13$.

Ogura, Y., 1957: Wave solutions of the vorticity equation for the $2 \frac{1}{2}$-dimensional model. $J$. meteor., 14, 60-64.

Defant, Fr. and H. Taba, 1957: The threefold structure of the atmosphere and the characteristics of the tropopause. Tellus, 9, 259-274.

—_- 1958: The strong index change period from January 1 to January 7, 1956. Tellus, 10, 225-242.

_- 1958: The break down of zonal circulation during the period January 8 to 13,1956 , the characteristics of temperature field and tropopause and its relation to the atmospheric field of motion. Tellus, 10, 430-450.

Wiin-Nielsen, A., 1959: On barotropic and baroclinic models, with special emphasis on ultralong waves. Mon. Wea. Rev., 87, 171-183.

\title{
時間的に変動する圏界面の力学的効果
}

\author{
新尚* \\ 気像庁電子計算室
}

大規模運動て対する大気モデルを成層圈まで払張することを考え，圈界面と地表面を座標含む，次のよろな $\sigma$ 座 標を鉛直方向にもつ $x, y, \sigma$-系を採用した。即ち，

$$
\sigma=\varepsilon \frac{p}{p_{T}} \text { : 成層圈, } \sigma=(1-\varepsilon) \frac{p-p_{T}}{p_{S}-p_{T}}+\varepsilon: \text { 対流圈。 }
$$

* 現在: 米気象局国立気象センター, 米国メリーランド州スートランド 
ここル $\varepsilon$ は $0<\varepsilon<1$ なる定数で圈界面の座標を示すから，層の鉛值方向のわけ方によってきめられるべきすのであ る。（例えば 2 層モデル（成層圈と対流圈）に対しては $\varepsilon=1 / 2,3$ 層モデルに対しては成層圏 1 層, 対流圏 2 層なら $\varepsilon=1 / 3$ がよい。）従ってこの $\sigma$ 座標では $\sigma=\varepsilon$ が内部境界面となる。

このモデルは対流圈と成層圏との力学的相互作用を扱うのに便利とできている。基本的仮定として圈界面は物質面 であるとし，その結果内部境界面としての圈界面 $(\sigma=\varepsilon)$ では $d \sigma / d t=0$ と拉いた。基礎運動方程式と熱の式及びこれ から導かれるエネルギ一方程式を示した。成層圈と対流圏との相互作用をあらわす運動エネルギ一交換の項 $\overline{\left(\phi_{T}{ }^{\prime} / g\right) \cdot}$ $\overline{\partial p_{T}{ }^{\prime} \partial t}\left(\phi_{T}{ }^{\prime}, p_{T}{ }^{\prime}\right.$ はとれぞれ圈界面のジオポテンシヤルと気圧) の役割を簡単な sin 型の波とついて調べた。短期 間の，対流圈と下部成層圏との運動エネルギーのやりとりとは，発達期にある長波の谷，峯が重要な役割を果してい ることがわかった。

更飞実沉についてみるために, Defant と Taba (1958) の解析結果から $\overline{\left(\phi_{T}{ }^{\prime} / g\right) \cdot \partial p_{T}{ }^{\prime} / \partial t}$ の值を計算した。限ら れた資料から一般的な結論は出せないが，その日々の值は，10 joule $\mathrm{m}^{-2} \mathrm{sec}^{-1}$ のオーダーで，その向きは擾乱が発 達しているときは上向きに，衰弱しているときは下向きととはげしく変る。従って時間平均してみると 1 joule $\mathrm{m}-2$ $\sec ^{-1}$ のオーダーとなる。

圈界面の気圧の時間変動を許すことは, 同時に, 対流圈全体とついて鉛直積分しても消えない発散をもたらすこと になるから，このよろなモデルで記述される対流圈の損乱は，Cressman (1958) のモデルの場合と同じ特性をあつ。 即ち，超長波のみかけ上の西進が扣さえられ，バロクリニックの場合には，更に不安定度曲線があたかも $\beta$-効果が 滅じたのと同じようと変る。このことを線型化した場合について示した。 